\title{
Experimental Investigation of Dynamic Response and Deformation of Aluminium Honeycomb Sandwich Panels Subjected to Underwater Impulsive Loads
}

\author{
Da-Lin Xiang, Ji-Li Rong, and Xuan He \\ School of Aerospace Engineering, Beijing Institute of Technology, Beijing 100081, China \\ Correspondence should be addressed to Ji-Li Rong; rongjili@bit.edu.cn
}

Received 20 April 2015; Revised 18 June 2015; Accepted 28 June 2015

Academic Editor: Evgeny Petrov

Copyright (c) 2015 Da-Lin Xiang et al. This is an open access article distributed under the Creative Commons Attribution License, which permits unrestricted use, distribution, and reproduction in any medium, provided the original work is properly cited.

\begin{abstract}
The response of aluminium sandwich panels with three thicknesses' core subjected to different underwater loading levels has been studied in the fluid-structure interaction (FSI) experiments. The transient response of the panels is measured using a three-dimensional (3D) Digital Image Correlation (DIC) system, along with high-speed photography. The full-field shape and displacement profiles of dry face sheets were recorded in real time compared with those of monolithic plate. The out-of-plane deflection and in-plane strain were quantified and analyzed. Three typical deformation modes of sandwich panel were identified. The results show that the core structure is crushed resulting in an initial large circular shape of deformation in the center area of panels. From this moment on, the panel is starting to act as a free vibration beam with initial velocities. The deformation modes consisted of homogeneous large deformation for both face sheets, obvious deformation border on wet face sheet, core node imprinting, remarkable wrinkled skin of deformation border, and a partial delamination and partial tear failure of the dry face. The blast-resistance of sandwich panel can be highly efficiently improved by increasing the thickness of core structure.
\end{abstract}

\section{Introduction}

Sandwich structures that combine face sheets and core topologies are wildly used in ship, submersibles, and other marine engineering [1-3]. These metallic structures are susceptible to damage due to dynamic loading from underwater explosion (UNDEX) and their dynamic response and shock resistance have attracted great interest from engineering communities. Structural dynamic response caused by UNDEX is complex due to FSI, high deformation rates, short loading time, material nonlinearity, and so forth. In this situation, it is quite difficult to make analytical models to accurately describe the deformation mechanism and dynamic response of sandwich panels [4-8]. Although some simulation studies were carried out, because of complex core topology structure, research objects were mainly for beam structure [9-11]. Hence, it is necessary to perform underwater shock experiments and accurately measure and analyze deformation and strain field in the response process of sandwich panel subjected to underwater impulse.
In recent years, several experimental apparatuses incorporating FSI effects were developed to test scaled structures. Wei and Dharmasena [12-14] designed a dyno-crusher apparatus based on a cardboard cylinder containing the water. They investigated the dynamic response of the sandwich panels with five core topologies (square-honeycomb, triangular honeycomb, multilayer pyramidal truss, triangular corrugation, and diamond corrugation) by detonating explosive in water. LeBlanc and Shukla [15-17] developed a conical shock tube facility simulating the free-field pressure wave expansion in an open water environment. The transient response of composite panels was measured using a 3D DIC system, along with high-speed photography. Though it is feasible to achieve underwater impulse loads, the abovementioned apparatus all need to use explosives, which poses a certain hazard in some circumstances.

A cylinder-shaped underwater shock simulator, without using explosive, was firstly utilized by Deshpande et al. to investigate the one-dimensional FSI of sandwich panel with steel face sheets and an aluminium foam core in 
TABLE 1: Al-2024-mechanical properties.

\begin{tabular}{ccccc}
\hline & $\begin{array}{c}\text { Density } \\
\rho\left(\mathrm{g} / \mathrm{cm}^{3}\right)\end{array}$ & Young's modulus & Shear modulus & Yield stress \\
& $E(\mathrm{GPa})$ & $\mathrm{G}(\mathrm{GPa})$ & $\sigma_{y}(\mathrm{MPa})$ & 75.8 \\
\hline $\mathrm{Al}-2024$ & 2.70 & 72.4 & 28 & \\
\hline
\end{tabular}

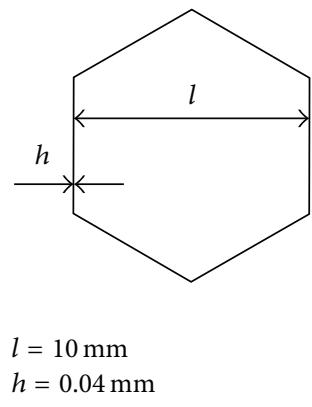

(a)

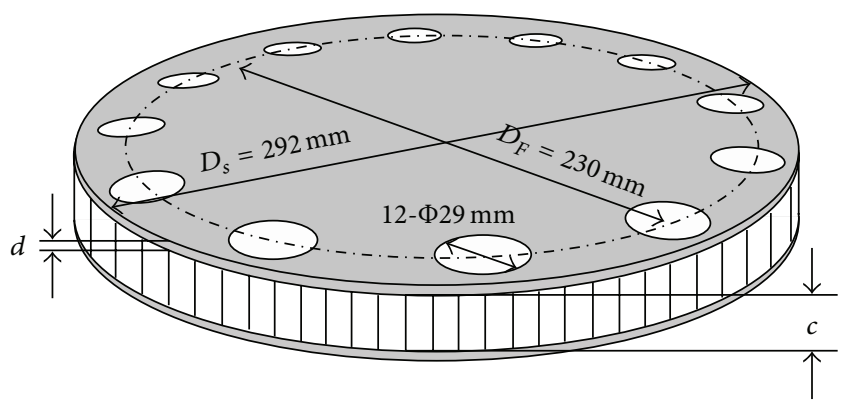

(b)

FIGURE 1: Geometry and dimensions of the specimens. (a) Geometry and dimension of a single cell and (b) geometry and dimension of a round sandwich panel.

the laboratory [18]. Their research showed that the shock wave generated in the water is independently adjusted by varying the projectile velocity and mass, respectively. A strong FSI effect is shown to exist and a decoupled model based upon the Taylor free-standing plate analysis underestimates the degree of core compression. McShane et al. used this technique to load free-standing sandwich plates with square-honeycomb core and corrugated core [19]. They found that an initial cavitation event was associated with the early acceleration of the front face and a second cavitation event occurred after the sandwich core has compressed, when the sandwich was behaving as a monolithic plate. Schiffer and Tagarielli [20] studied the structural responses and cavitation processes through one-dimensional experiments and simulation. They pointed out the details of water cavitation strongly influencing the pressure histories on the sandwich structures and the imparted impulse is very sensitive to initial static pressure and strength of the foam core. In parallel studies, a novel diffuser type pressure tube was designed and the specimen panel out-of-plane full-field displacements were measured by means of shadow moiré and high-speed photography [21]. Using this experiment setup, Mori et al. studied the deformation and fracture modes of metallic sandwich structures $[22,23]$. The studies showed that sandwich panels can lead to a reduction in panel deflection compared to solid panels of equal mass per unit area. The failure modes consisted of core crushing, core node imprinting/punchthrough/tearing, and stretching of the front face sheet for the pyramidal truss core panels. The work points out the synergies between structure geometry, materials, manufacturing methods, and threat levels as manifested by the strength of the impulse.

The present study aims to investigate the dynamic behavior and deformation mode of clamped circular aluminium honeycomb sandwich panel when experimentally subjected to underwater impulsive loading. The shock pressure histories, generated in a laboratory-scale water shock tube apparatus, are well captured. Sandwich panels with three thicknesses' core layer were chosen to be carried out in ten loading levels. A high-speed photography system with two cameras is utilized to capture real-time images of the panel during underwater blast loading. The full-field data of the deformation during the shock events is obtained utilizing $3 \mathrm{D}$ DIC techniques and analyzed compared with that of solid plate. Postmortem visual observations of the test specimens are carried out to identify the deformation modes. The results are analyzed in normalized forms to gain insight into underlying trends that can be explored in the design of blastresistance for sandwich panels.

\section{Specimen}

The round specimens used in the tests consist of two face sheets and a core of honeycomb [24]. The mechanical properties of face sheets are provided in Table 1. The HexWebs aluminium honeycomb core comprises a square array of hexagonal cells. The cell length $l$ and wall thickness $h$ are indicated in Figure 1(a). The specimen with a diameter $\left(D_{s}\right)$ of $292 \mathrm{~mm}$ is manufactured by water-jet machining, and 12 through holes are machined and placed on the $230 \mathrm{~mm}$ diameter $\left(D_{F}\right)$ circumference, each hole having a diameter $(\Phi)$ of $29 \mathrm{~mm}$, Figure 1(b). The three different thicknesses of core structure $c$ are $4.0,7.5$, and $12.3 \mathrm{~mm}$, respectively. The thicknesses of face sheets $d$ are constant and equal to $1.0 \mathrm{~mm}$. The mass per unit area $(\bar{M})$ of the sandwich panels is 5.20 , 5.36 , and $5.58 \mathrm{~kg} / \mathrm{m}^{2}$, respectively.

The diameter of the specimen exposed to the water blast pressure was chosen to be $D_{I}=152.4 \mathrm{~mm}$. To obtain a clamped boundary condition, 12 ring spacers were inserted to 


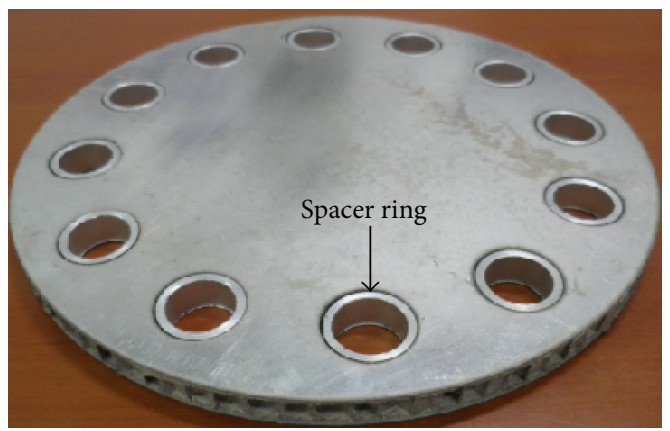

(a)

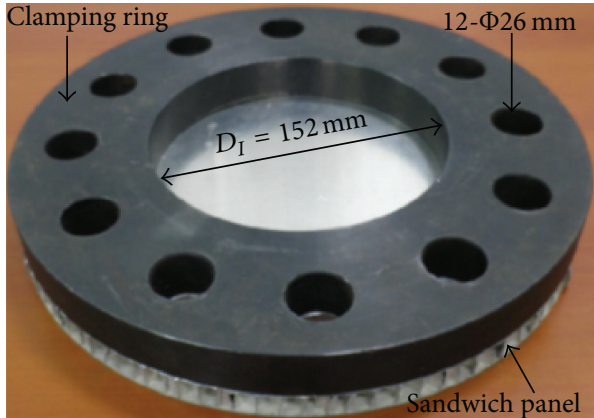

(b)

FIgURE 2: A specimen panel and a panel with a clamping ring. (a) Solid-ring spacers were employed to prevent core crushing while fastening the clamping ring. (b) A steel ring was employed to clamp the sandwich panel to the anvil tube with 12 screws.

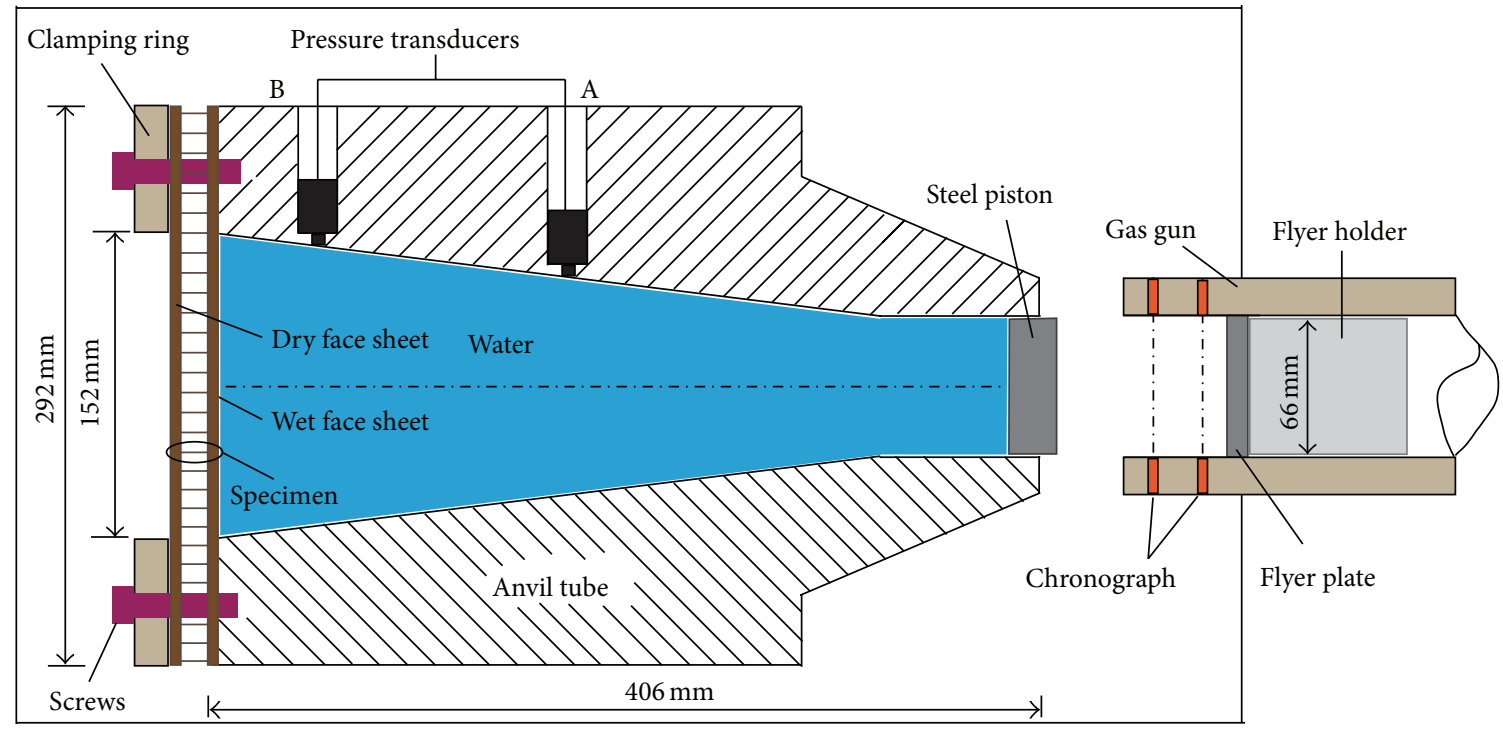

FIGURE 3: Schematic of water chamber with divergent diffuser.

prevent core crushing during the clamping process as shown in Figure 2.

\section{Underwater Shock Experiments}

3.1. Underwater Shock Loading Device. Generally, the freefield incident UNDEX impulsive loading in a fluid can be idealized as exponential pressure decay:

$$
p=p_{m} e^{-t / \theta}
$$

where $p_{m}$ is the peak pressure and $\theta$ is a characteristic decay time [25]. The free-field momentum I (impulse/area) is given by

$$
I=\int_{0}^{t} p d t .
$$

Therefore, three loading parameters, $p_{m}, \theta$, and $I$, are the interest for each underwater shock experiment. In order to reproduce in a laboratory setting underwater explosive loading conditions, a scaled FSI experimental setup was developed by Espinosa et al. [21]. In the FSI setup, a water chamber made of a steel tube is incorporated into a gas gun apparatus (Figure 3). The specimen panel and a $22 \mathrm{~mm}$ thick piston are installed at the rear end and the front (right) end, respectively. The exponentially decaying pressure history is produced by impacting the piston with a $5 \mathrm{~mm}$ thick flyer plate launched by a gas gun. The pressure histories are measured by dynamic high-pressure transducers installed in the positions of $\mathrm{A}$ and $\mathrm{B}$. The peak pressure, $p_{m x}$, the initial decay time, $\theta_{0}$, and impulse of shock wave can be given by

$$
\begin{aligned}
p_{m x} & =V_{0}\left(\frac{D}{D_{x}}\right)^{2} \frac{s f}{s+f}, \\
\theta_{0} & =-\frac{2 h}{C} \ln \left[\frac{s-f}{s+f}\right], \\
I_{m x} & =\sum_{0}^{\infty} p_{m x}\left[\frac{s-f}{s+f}\right]^{n} \Delta t \approx p_{m x} \theta_{0},
\end{aligned}
$$




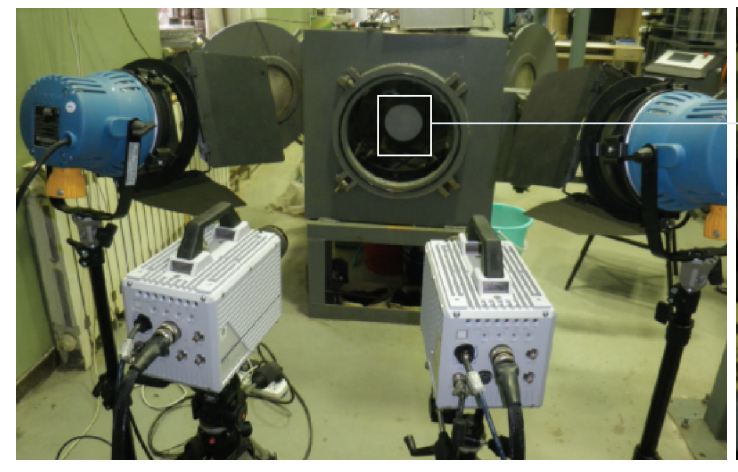

(a)

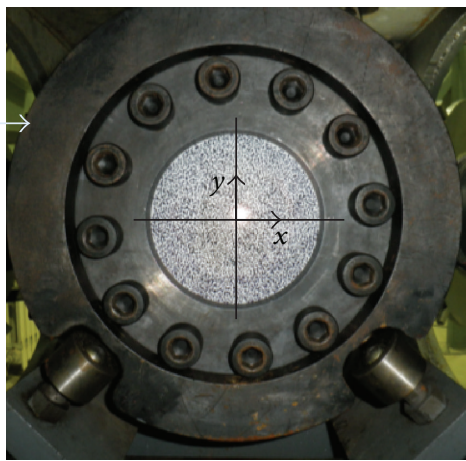

(b)

FIGURE 4: Photos of the experimental setup: (a) global view of 3D DIC measurement system with two high-speed digital cameras mounted in a stereo configuration and two light spots based on FSI experimental setup; (b) area of interest of the clamped test specimen painted with a black and white speckle pattern.

where $V_{0}$ is the impact velocity of flyer plate, $h_{s}$ is the thickness of the flyer plate, $f=(\rho C)_{f}$ and $s=(\rho C)_{s}$ are the acoustic impedance values of water and solid, $D$ and $D_{x}$ are the diameters of the water tube at impact and pressure prediction locations, respectively, $n$ is the number of wave reverberations in the flyer plate, and $\Delta t$ is the time required for the elastic longitudinal wave to twice traverse the flyer plate.

3.2. Experimental Procedure. The recent fast development of DIC techniques is a nonintrusive optical technique for capturing complex heterogeneous displacement with relative ease in different domains of engineering [26, 27]. A 3D DIC measurement system including two synchronized high-speed cameras in a stereoscopic setup, two halogen lamps, and specialized software was used to capture the transient response of the back (dry) face sheet of the panels, Figure 4(a).

The specimen with a randomized speckle pattern was clamped using a steel ring with 12 screws at the rear of anvil tube, Figure 4(b). Two high-speed cameras, Photron SA5, were positioned behind the anvil tube to record the speckles on the dry face sheet. The distance from the lens of the camera to the specimen was about $1.5 \mathrm{~m}$ and each camera was angled at approximately $4^{\circ}$ with respect to the symmetry plane. The cameras were calibrated by a grid pattern, and a framing rate of 50,000 frames/s (an interframe time of $20 \mu$ s) was set with an image resolution of $512 \times 272$ pixels for $1 \mathrm{~s}$ time duration.

A TTL signal can be generated when the flyer plate impacts the piston. Thus, the pressure transducers and two high-speed cameras will be synchronized, triggered to record the pressure data and deformation images upon the arrival of shock wave. The postprocessing of deformation images was performed with the VIC-3D software to get the full-field shape and deformation measurements $[16,17]$.

\section{Results and Discussion}

4.1. Underwater Pressure History. In order to describe and explain the dynamic response of panels, occurring pressure wave and the resulting dynamic loading are investigated. All the sandwich panels were tested using a flyer plate, $5.0 \mathrm{~mm}$ thick, launched with different velocities. The amplitudes and overall trends of the pressure histories predicted by the experiments are shown in Figure 5. At this point it must be mentioned that the starting point of time was the triggering moment of the measurement system. The plots show that the pressure histories measured were well captured by the dynamic high-pressure transducers during the time period of $200 \sim 600 \mu \mathrm{s}$. It confirms the fact that the pressure wave is similarly spherical and propagates in a radial manner [2123]. The recorded pressure histories measured at position $A$, which exhibited steep rise, peak pressure of about $38.6 \mathrm{MPa}$, $56.6 \mathrm{Mpa}$, and 76.6 MPa, respectively, and subsequent exponential decay, are similar to that of the free-field incident UNDEX impulsive loading. The reflection from the specimen is observed as a second peak on the pressure histories at position $\mathrm{B}$, which result in the large delay time and impulse loads.

The peak pressures at different positions are calculated using (3), and the decay time of the initial incident shock wave is about $26.8 \mu$ s predicted by (4). The results are summarized in Table 2. Due to energy attenuation, the experimental peak pressures measured at positions $\mathrm{A}$ and $\mathrm{B}$ are smaller than that predicted by an average of $8.1 \%$. The decay times of shock wave at positions $\mathrm{A}$ and $\mathrm{B}$ can be obtained according to the pressure profiles. The impulse predicted by (5) is smaller than the experimental values, especially at position $\mathrm{B}$ because of the stack of reflection wave.

4.2. Typical Deformation Histories. To obtain 3D full-field deformation a reduced area of interest of $120 \times 46 \mathrm{~mm}^{2}$ is selected. Figure 6 shows the panel out-of-plane displacement field during the shock at different time steps (from 320.0 to $1820 \mu \mathrm{s})$. The major component is the out-of-plane displacement $w$. Notice the shape of the deformation, which is approximating a circular shape in the first $800 \mu$ s and evolves into a sinusoidal shape after $1020 \mu \mathrm{s}$.

After impact, the shock wave travels through the water and arrives at the clamped panel, creating transient underwater impulsive loads. Initially at $320 \mu$ s, the pressure is 

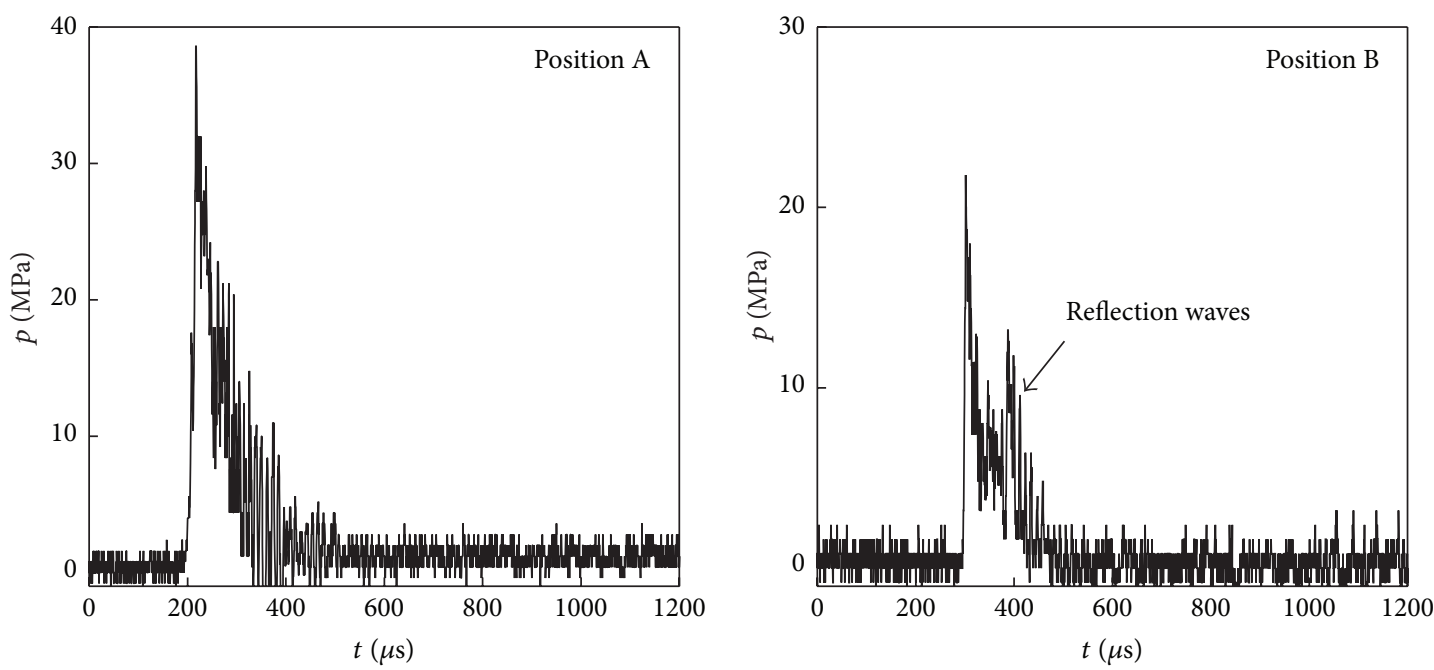

(a) Impact velocity of $V_{0}=77.0 \mathrm{~m} / \mathrm{s}, c=4 \mathrm{~mm}$
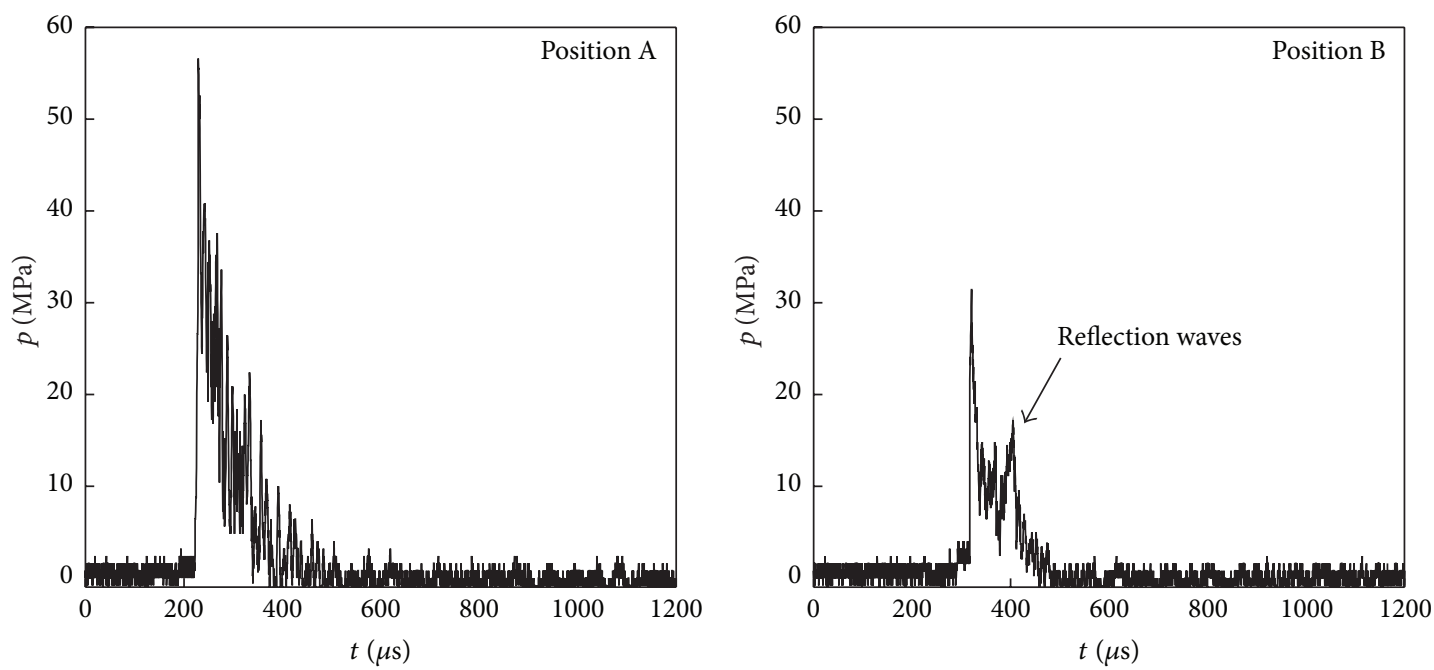

(b) Impact velocity of $V_{0}=112.3 \mathrm{~m} / \mathrm{s}, c=7.5 \mathrm{~mm}$
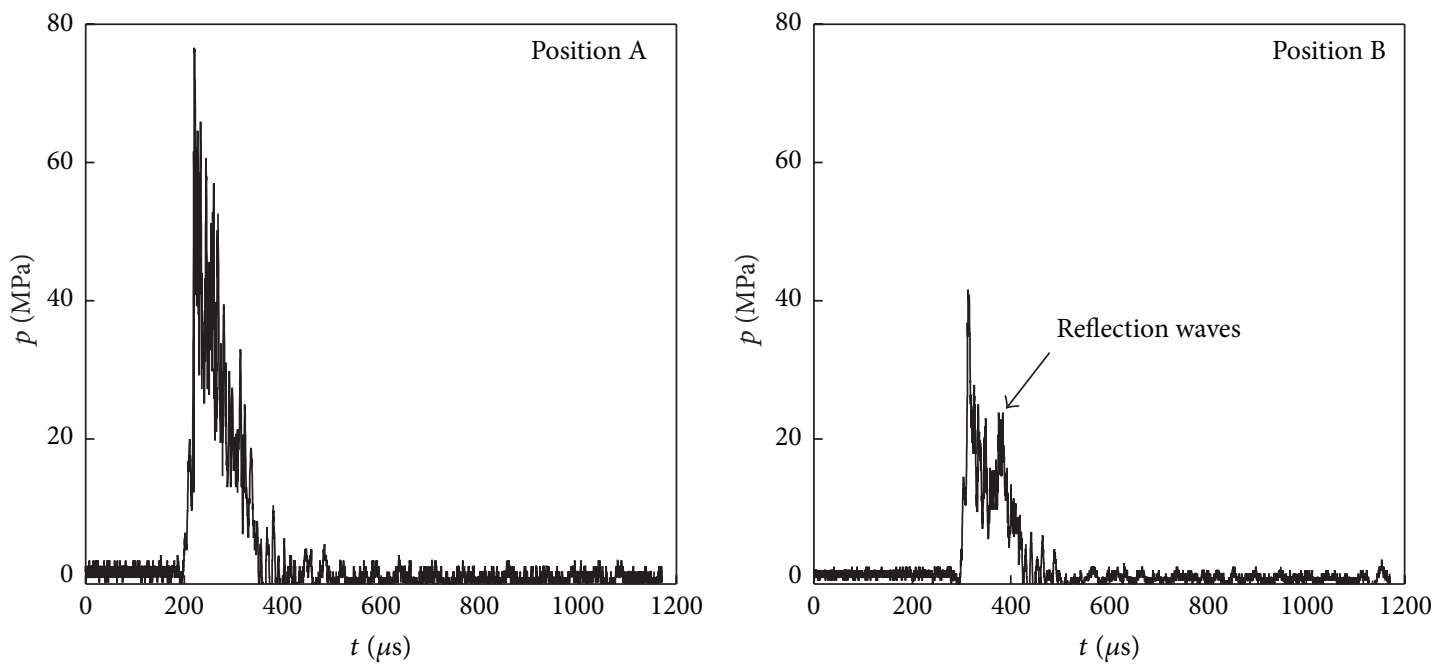

(c) Impact velocity of $V_{0}=150.0 \mathrm{~m} / \mathrm{s}, c=12.3 \mathrm{~mm}$

Figure 5: Typical pressure-time history at different load intensities. 
TABLE 2: Characteristic parameters of underwater impulsive loads.

\begin{tabular}{|c|c|c|c|c|c|c|c|c|c|c|c|c|c|}
\hline \multirow[b]{2}{*}{$\begin{array}{l}\text { Impact } \\
\text { velocity }(\mathrm{m} / \mathrm{s})\end{array}$} & \multicolumn{5}{|c|}{ Position A } & \multicolumn{5}{|c|}{ Position B } & \multicolumn{3}{|c|}{ Specimen } \\
\hline & & $\begin{array}{c}p_{m A} \\
(\mathrm{MPa})\end{array}$ & $\begin{array}{c}\theta_{\mathrm{A}} \\
(\mu \mathrm{s})\end{array}$ & & $\begin{array}{c}I_{\mathrm{A}} \\
(\mathrm{kPa} \cdot \mathrm{s})\end{array}$ & & $\begin{array}{c}p_{m \mathrm{~B}} \\
(\mathrm{MPa})\end{array}$ & $\begin{array}{c}\theta_{\mathrm{B}} \\
(\mu \mathrm{s})\end{array}$ & & $\begin{array}{c}I_{\mathrm{B}} \\
(\mathrm{kPa} \cdot \mathrm{s})\end{array}$ & $\begin{array}{c}p_{m s} \\
(\mathrm{MPa})\end{array}$ & $\begin{array}{c}\theta_{\mathrm{s}} \\
(\mu \mathrm{s})\end{array}$ & $\begin{array}{c}I_{\mathrm{s}} \\
(\mathrm{kPa} \cdot \mathrm{s})\end{array}$ \\
\hline & Exp. & Equation (3) & Exp. & Exp. & Equation (5) & Exp. & Equation (3) & Exp. & Exp. & Equation (5) & Equation (3) & Pred. & Equation (5) \\
\hline 77.0 & 38.6 & 42.1 & 61.8 & 1.857 & 1.128 & 21.8 & 23.3 & 50.3 & 0.980 & 0.624 & 20.5 & 48.6 & 0.549 \\
\hline 112.3 & 56.6 & 61.4 & 61.3 & 2.503 & 1.645 & 31.4 & 34.0 & 52.5 & 1.272 & 0.911 & 29.8 & 48.6 & 0.799 \\
\hline 150.0 & 76.6 & 82.0 & 63.0 & 4.378 & 2.198 & 41.6 & 45.4 & 51.7 & 1.579 & 1.217 & 39.9 & 48.6 & 1.069 \\
\hline
\end{tabular}
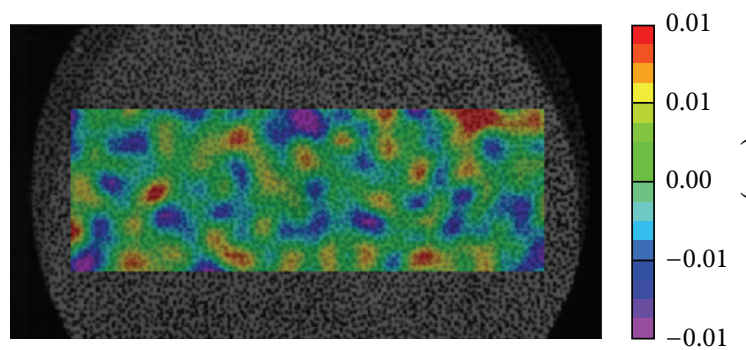

(a) $t=320 \mu \mathrm{s}$

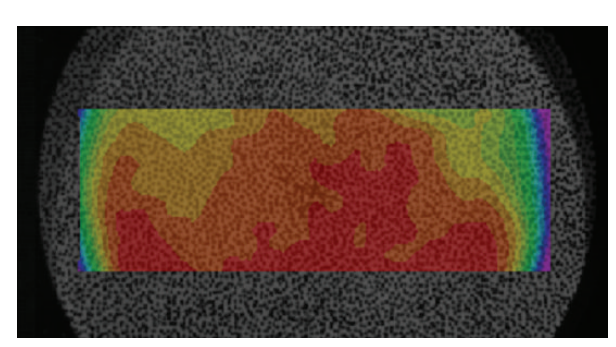

(c) $t=520 \mu \mathrm{s}$

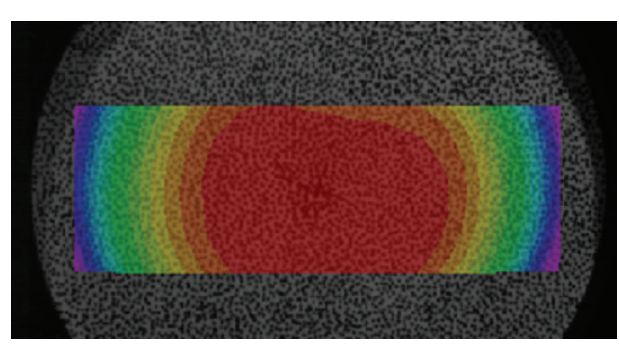

(e) $t=700 \mu \mathrm{s}$

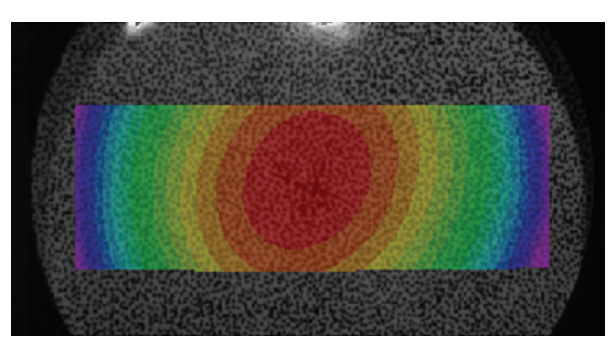

(g) $t=1280 \mu \mathrm{s}$

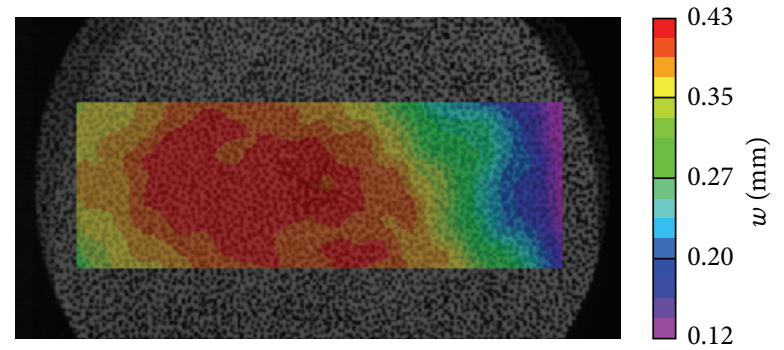

(b) $t=460 \mu \mathrm{s}$
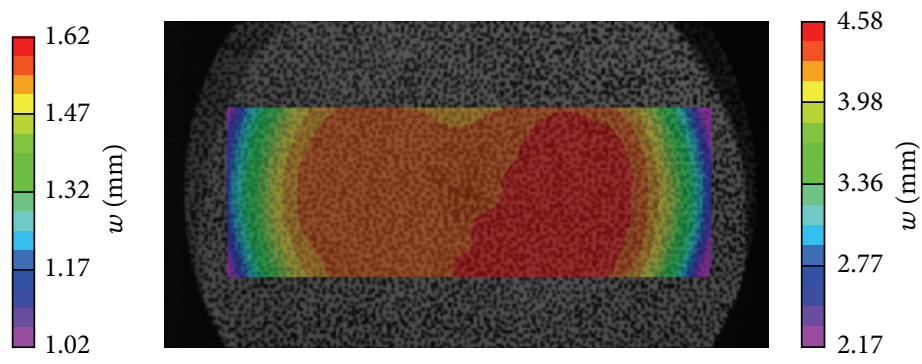

(d) $t=660 \mu \mathrm{s}$
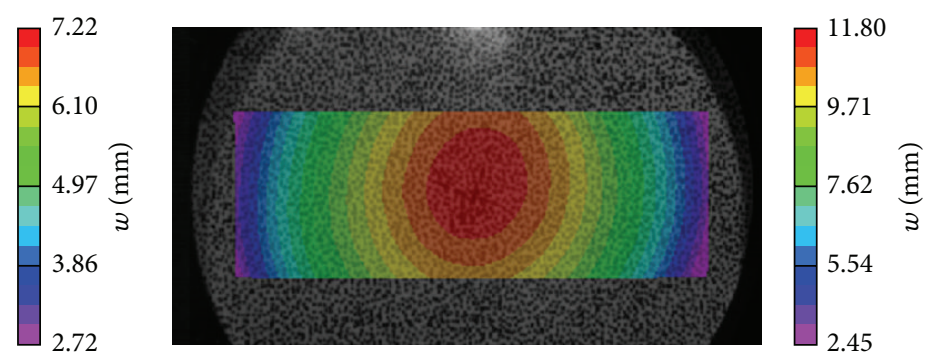

(f) $t=1020 \mu \mathrm{s}$
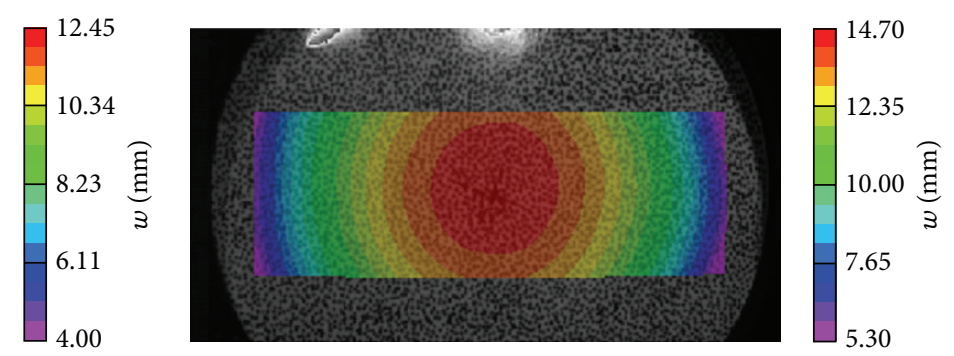

(h) $t=1820 \mu \mathrm{s}$

Figure 6: Full-field resultant displacements at different time steps $(\mathrm{mm})$ for aluminium honeycomb sandwich panel $\left(c=4.0, V_{0}=77.0 \mathrm{~m} / \mathrm{s}\right.$, $p_{m s}=20.47 \mathrm{MPa}, \theta_{0}=26.8 \mu \mathrm{s}$, and $\widehat{I}=0.630$ ). 


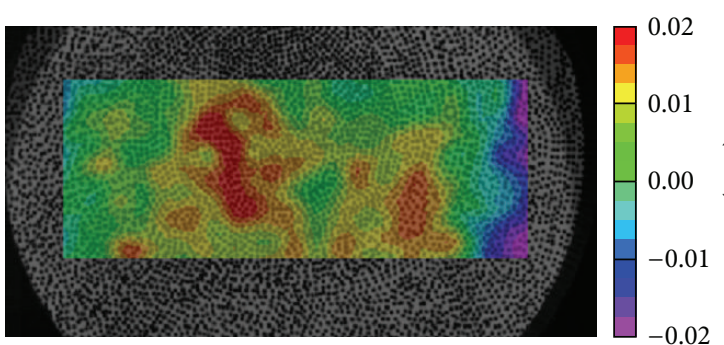

(a) $t=320 \mu \mathrm{s}$

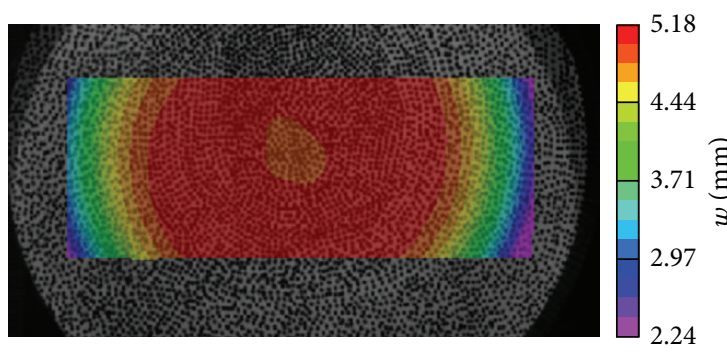

(c) $t=500 \mu \mathrm{s}$

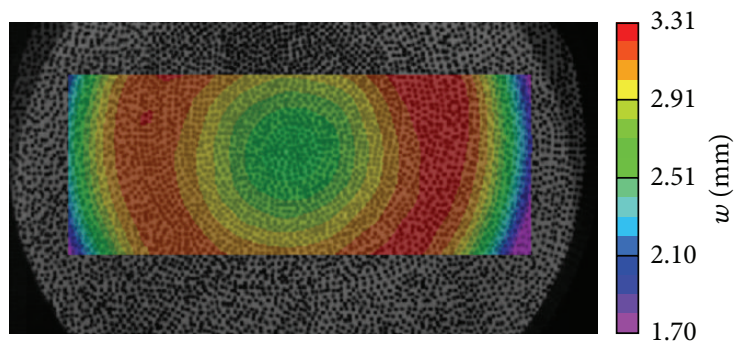

(b) $t=440 \mu \mathrm{s}$

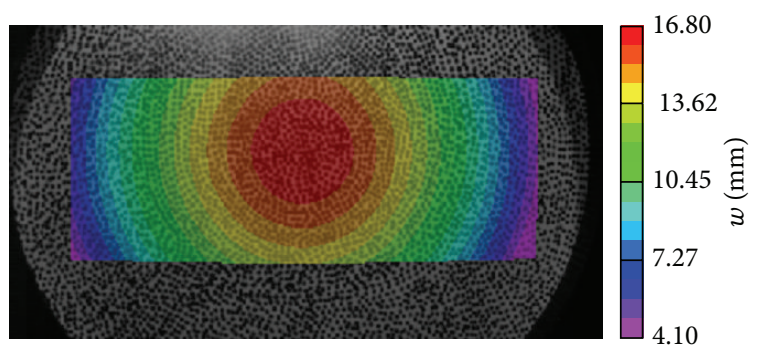

(d) $t=1020 \mu \mathrm{s}$

Figure 7: Typical full-field resultant displacements at different time steps for aluminium monolithic plate $\left(3.0 \mathrm{~mm}\right.$ thick, $V_{0}=97.7 \mathrm{~m} / \mathrm{s}$, $p_{m s}=26.0 \mathrm{MPa}, \theta_{0}=26.8 \mu \mathrm{s}$, and $\left.\widehat{I}=0.453\right)$.

maximum but highly localized at the wet face sheet of the panel. After $320 \mu \mathrm{s}$, the pressure decreases rapidly in amplitude but expands over the whole panel's wet face sheet. The impulse hence imparts momentum to the wet face sheet during a very short loading period, from 320 to $460 \mu \mathrm{s}$. This momentum is large enough to continuously deform the wet face sheet after termination of the loading from the shock wave. Then, the core is crushed by the wet face sheet and consequently the wet face sheet is decelerated by the core while the core and the dry face of the sandwich panel are accelerated.

The out-of-plane displacement field history of $\mathrm{Al}$ plate is shown in Figure 7 to compare the deformation process. It can be found that, in the early stage of the deformation, the maximum deformation of the $\mathrm{Al}$ plate appeared at outer edge, while that of sandwich panel appeared in the center area. The nondimensional impulse applied to the plate was calculated based on $p_{m s}, \theta_{0}$, and the material properties of the specimen; that is, $\widehat{I}=I_{s} /\left(\bar{M} \cdot \sqrt{\sigma_{y} / \rho}\right)[8]$. The maximum deflection $w_{\max }$ was measured to be $14.7 \mathrm{~mm}$ and $16.8 \mathrm{~mm}$ for sandwich panel and monolithic plate, respectively. It is obvious that the dry face deflection sandwich panel with the mass of $5.20 \mathrm{~kg} / \mathrm{m}^{2}$ subjected to the larger impulse loading is less than that observed in monolithic plate with mass of $8.10 \mathrm{~kg} / \mathrm{m}^{2}$.

The displacement and velocity profiles along the dry face sheet's $x$-axis are shown in Figure 8. Notice that the profiles are plotted from -60 to $60 \mathrm{~mm}$, while the boundaries are located at -76 and $76 \mathrm{~mm}$. It is very clear from Figure 8(a) that the deformation is almost constant over the whole panel until $800 \mu$ s.

Because of the clamped boundary, speckle patterns close to the dry face sheet's borders are constrained and only have a very limited initial velocity. When the core, located in the central panel, has been crushed at $460 \mu \mathrm{s}$, the wet face sheet and compacted core have the same given velocity of $14.5 \mathrm{~m} / \mathrm{s}$ (see Figure 8(b)). From this moment on, the panel is starting to act as a rigid-perfectly plastic clamped beam with initial transverse velocity, which is consistent with the assumption of Fleck and Deshpande [4]. Only the inertia forces of the panel's mass cause the panel to deform further. Therefore all points in the central area of dry face sheet are forced to move out of plane, resulting in an initial circular shape of deformation. The dry face sheet obtains a maximum deform velocity of $22 \mathrm{~m} / \mathrm{s}$ at $660 \mu \mathrm{s}$. This is clear from Figure 8(a) where the deformation is almost constant over the whole panel until $800 \mu \mathrm{s}$. And this explains why the shape of deformation evolves towards a sinusoidal shape, just as the first bending modal mode shape of the plate.

Figure 9 presents the evolution of the normal in-plane strains $E_{x x}$. It can be noticed that until time $800 \mu$ s the maximum normal strains occur close to the boundaries. Points close to the clamping area are constrained and higher strains occur in these areas. Further, when inertia forces are taking over, strains are developing in the center of the dry face sheet reaching maximum values of $0.016(16,000 \mu$ strain). The strain rates during the whole process are included in the intermediate rate domain (strain rates between $1 \mathrm{~s}^{-1}$ and $100 \mathrm{~s}^{-1}$, [28]). From 320 to $1280 \mathrm{~ms}$, maximum strain rates of $50.5 \mathrm{~s}^{-1}$ occur close to the corners of the dry face sheet. 


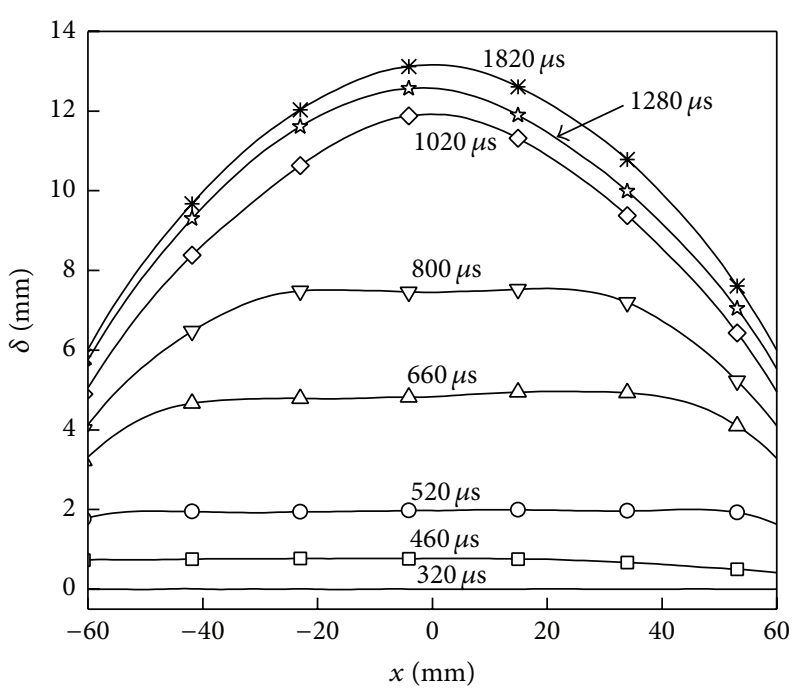

(a)

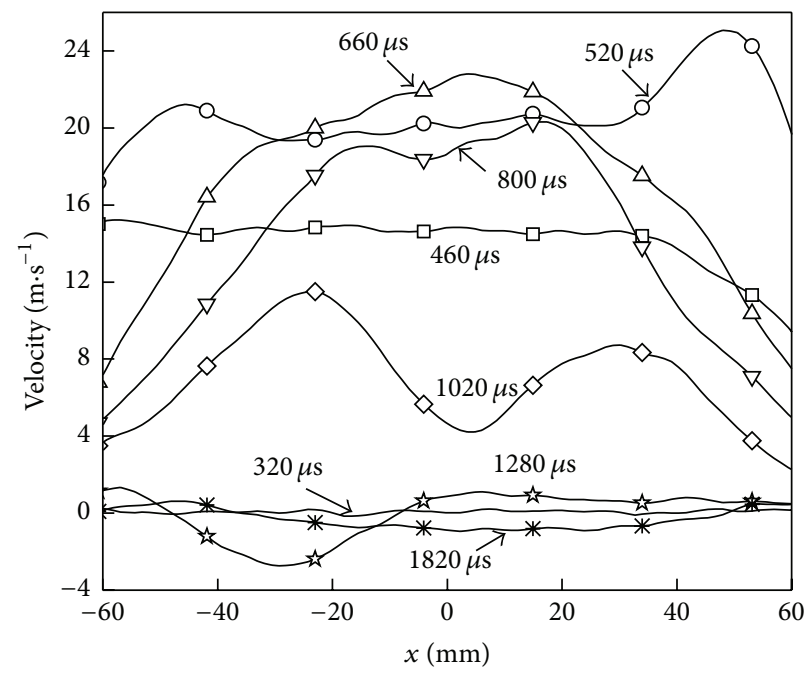

(b)

Figure 8: (a) Displacement profile along the $x$-axis; (b) velocity profile along the $x$-axis.

\subsection{Deformation Modes}

4.3.1. Case I. The sandwich panel with a thicknesses core structure $c$ of $12.3 \mathrm{~mm}$ was tested using a flyer plate launched at a velocity of $140.0 \mathrm{~m} / \mathrm{s}$. This resulted in a peak pressure $p_{m s}$ of $37.21 \mathrm{MPa}$ and a characteristic decay time $\theta_{0}$ of $26.8 \mu \mathrm{s}$. The corresponding applied impulse $I_{s}$ was $18.2 \mathrm{~N} \cdot \mathrm{s}$ and the nondimensional applied impulse $\widehat{I}$ was 1.067 . The maximum rear deflection is measured to be $16.0 \mathrm{~mm}$ and the nondimensional maximum deflection $w_{\max } / L=0.211$, where $L=76 \mathrm{~mm}$ is half the specimen span.

Figure 10 shows images of aluminium honeycomb sandwich panel after the test. The plastic deformation of the back face sheet was homogeneous, and that of the wet face sheets shows a transition from center to periphery and the folds deformations were observed near the bolt holes. As observed in previous studies [21], the FSI configuration employing bolts to achieve a clamped boundary condition allows some in-plane deformation of the specimen at the boundary. Evidence of slippage and hole ovalization is reported in Figure 10(d).

The specimens subjected to nondimensional impulses of $\widehat{I}=0.712$ and $\widehat{I}=1.147$ were cut in half by waterjet machining and are shown in Figure 11. In both cases significant core crushing close to the boundary is observed. However, the extent of core crushing in the center of the panel is different. Only the largest impulse resulted in significant plastic buckling of the core webs in the center of the section panel.

4.3.2. Case II. A panel with a thicknesses core structure $c$ of $4.0 \mathrm{~mm}$ was tested using a flyer plate shot and impact velocity of $77.0 \mathrm{~m} / \mathrm{s}$. This resulted in a peak pressure $p_{m s}$ of $20.47 \mathrm{MPa}$. The corresponding applied impulse $I_{s}$ was $10.0 \mathrm{~N} \cdot \mathrm{s}$ and the nondimensional applied impulse $\widehat{I}$ was 0.630 . Figure 12 shows photographs of the panel after testing.
The maximum rear deflection was $14.7 \mathrm{~mm}$ and thus the nondimensional maximum deflection $w_{\max } / L=0.193$.

Figure 12 reports the observed deformation modes in this experiment. In this case, the difference is much more prominent. The deformation area of the wet face sheet shows very distinct boundaries, Figure 12(b). Due to large deformation, a partial delamination occurred between the wet face sheet and the core structure, and the whole structure buckling appeared, as observed in Figure 12(c). After the experiment, the panel was sectioned and imaged as shown in Figure 13. It appears that almost complete core crashing occurred over the entire span of the sandwich structure.

4.3.3. Case III. The sandwich panel with a thicknesses core structure $c$ of $7.5 \mathrm{~mm}$ was tested using a flyer plate launched at an impact velocity of $137.9 \mathrm{~m} / \mathrm{s}$. This resulted in a peak pressure $p_{m s}$ of $36.65 \mathrm{MPa}$. The corresponding applied impulse $I_{s}$ was $17.91 \mathrm{~N} \cdot \mathrm{s}$ and the nondimensional applied impulse $\widehat{I}$ was 1.094. Figure 14 shows photographs of the panel after testing. The maximum rear deflection was measured to be $22.3 \mathrm{~mm}$ and the nondimensional maximum deflection $w_{\max } / L=$ 0.293 .

The failure modes observed in this experiment are reported in Figure 14. In contrast to the case with Case II, the sandwich panel exhibited the same behavior for the dry and the wet face sheets: the deformation for both was homogeneous and the border of wet face sheet's deformation exhibits remarkable wrinkled skin, Figure 14(b). Obvious imprints are observed on the wet face sheet, Figure 14(c). Due to constraint of clamping ring, local border damage appearing on the constraint boundary of the dry face sheet is observed in Figure 14(d).

After the experiment, the panel was sectioned and imaged as shown in Figure 15. The specimen shows a homogeneous overall deformation in both face sheets. The core was completely collapsed at the boundary, which is consistent with 


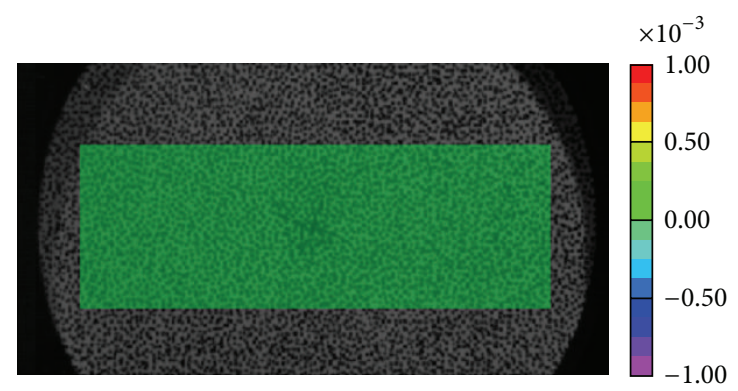

(a) $t=320 \mu \mathrm{s}$

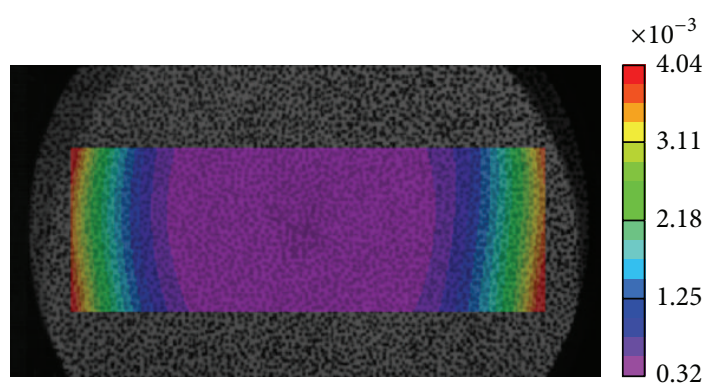

(c) $t=520 \mu \mathrm{s}$

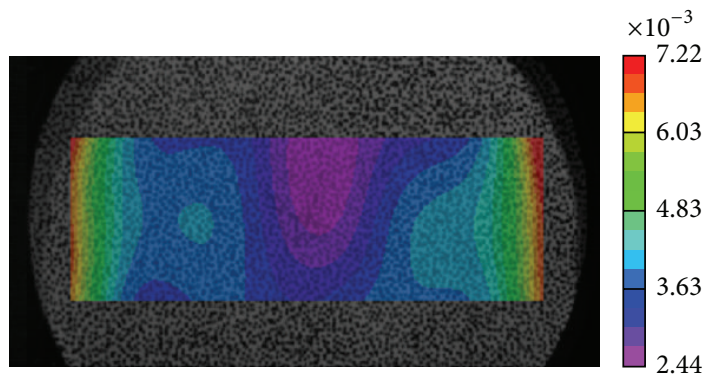

(e) $t=800 \mu \mathrm{s}$

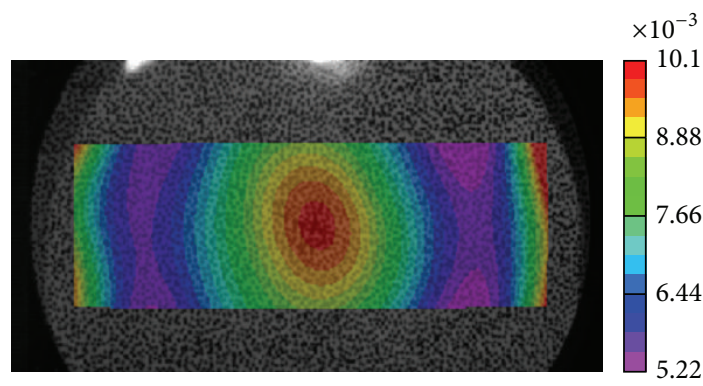

(g) $t=1280 \mu \mathrm{s}$

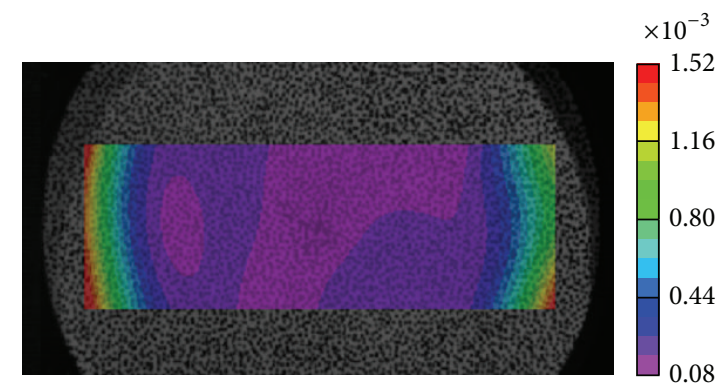

(b) $t=460 \mu \mathrm{s}$

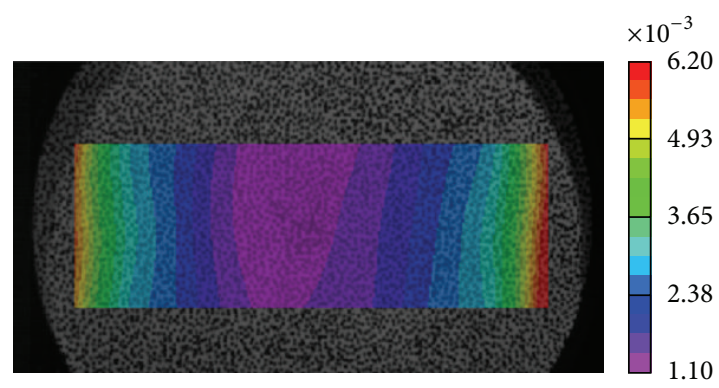

(d) $t=660 \mu \mathrm{s}$

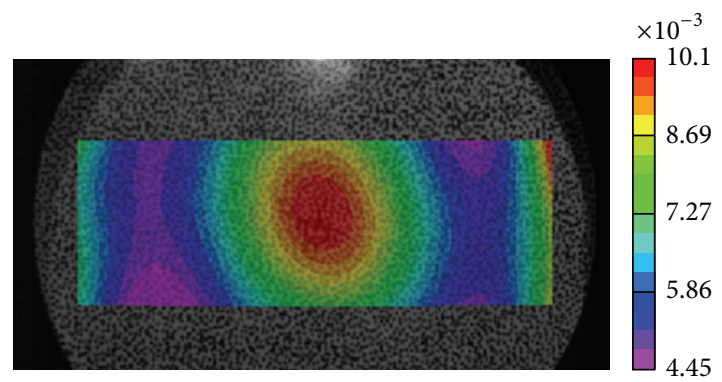

(f) $t=1020 \mu \mathrm{s}$

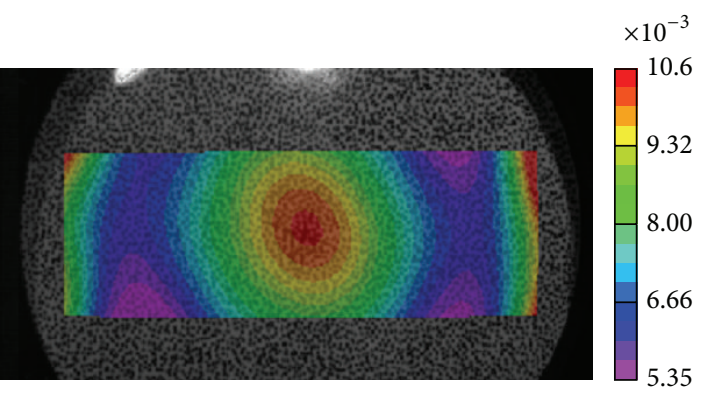

(h) $t=1820 \mu \mathrm{s}$

Figure 9: True strain field $E_{x x}$ at different time steps.

the boundary condition depicted in Figure 13. And a partial tear failure occurred between the dry face and the clamping ring, as shown in Figure 15(b).

4.4. Shock Resistance. Ten experiments were conducted on aluminium sandwich panels with flyers impact velocities between $77.0 \mathrm{~m} / \mathrm{s}$ and $150.6 \mathrm{~m} / \mathrm{s}$. Maximum deflection and deformation/failure mode of sandwich panels with three core thicknesses were carried out at difference levels of blast as measured by $I_{s} /\left(\bar{M} \cdot \sqrt{\sigma_{y} / \rho}\right)$ and presented in Table 3 . The initial peak pressure $p_{m s}$ and impulse $I_{s}$ were predicted values by (3) and (5), respectively, rather than experimental value. The results show that the normalized maximum deflection of sandwich panels with the same core thickness will increase linearly with the dimensionless impulse. The deformation/failure mode also gradually evolves from Case 


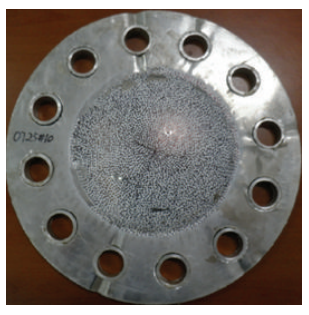

(a)

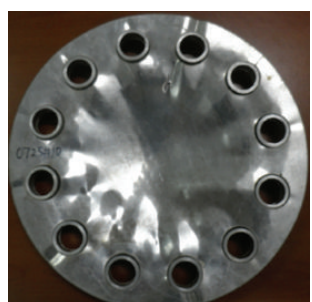

(b)

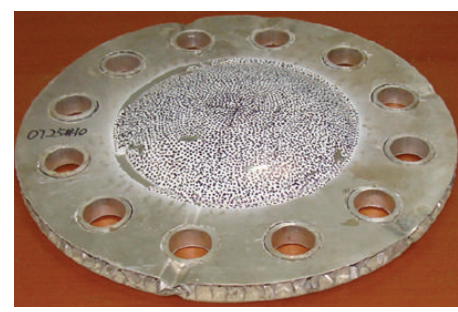

(c)

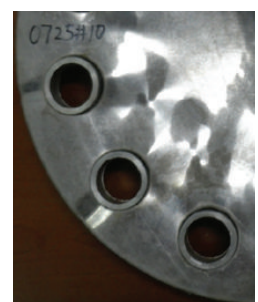

(d)

FIGURE 10: Sandwich panel after impulsive loading, $c=12.3 \mathrm{~mm}, \widehat{I}=1.067$ : (a) and (b) show the dry and the wet face sheets; (c) shows a side view; (d) detail of the wet face sheets near the bolt holes.

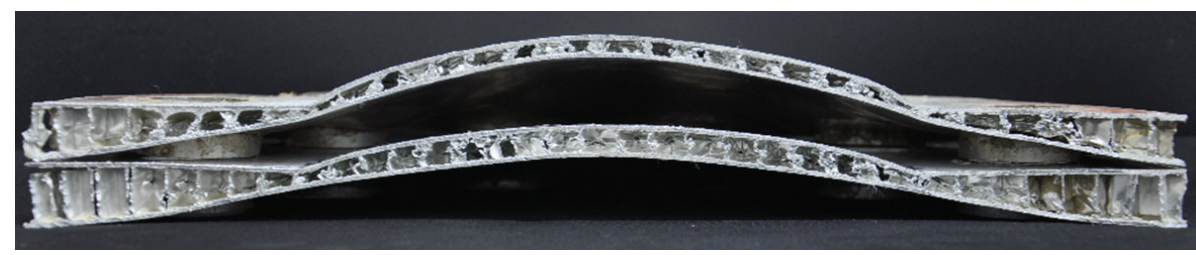

Figure 11: Cross section of sandwich panel after impulsive loading. The upper panel is the case of $\widehat{I}=1.147$ and the lower panel is the case of $\widehat{I}=0.712$.

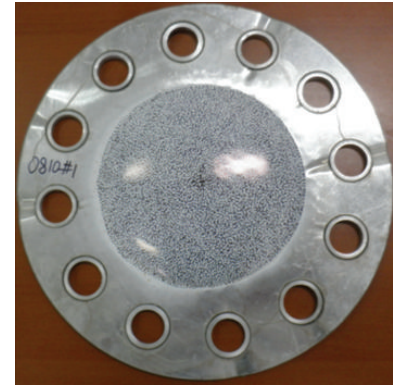

(a)

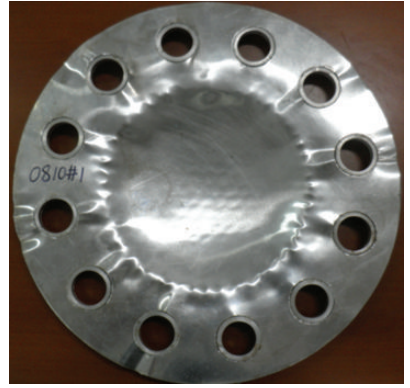

(b)

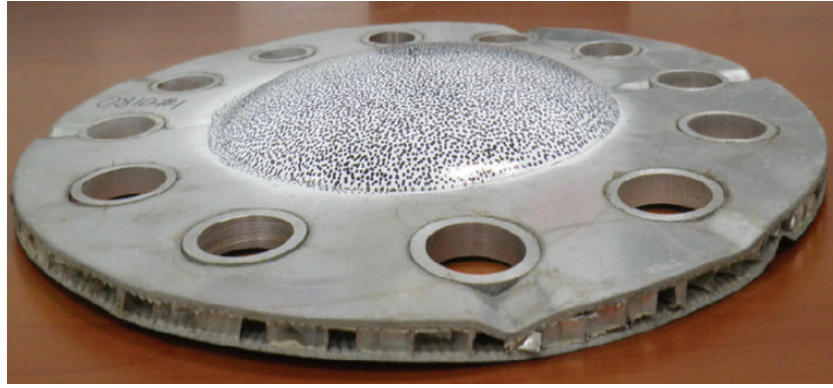

(c)

FIGURE 12: Sandwich panel after impulsive loading, $c=4.0 \mathrm{~mm}, \widehat{I}=0.630$ : (a) and (b) show the dry and the wet face sheets; (c) shows a side view.

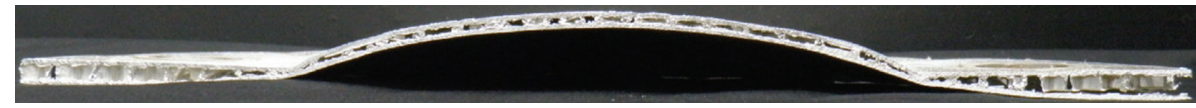

Figure 13: Cross section of sandwich panel after impulsive loading for the case of $\widehat{I}=0.630$.

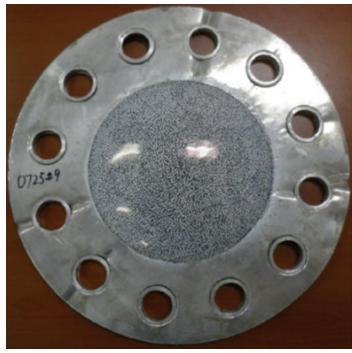

(a)

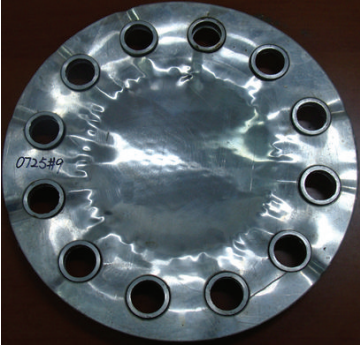

(b)

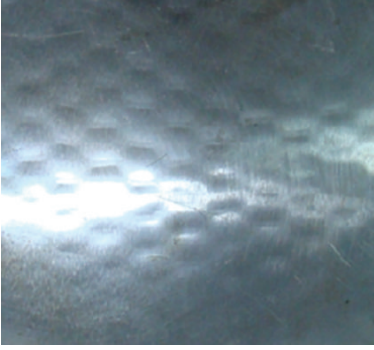

(c)

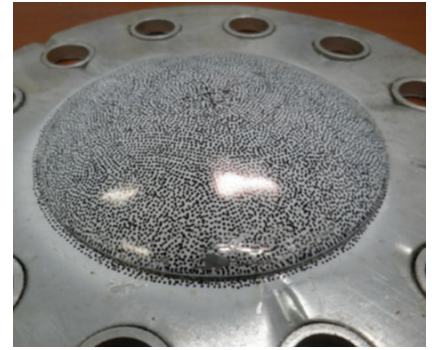

(d)

FIGURE 14: Sandwich panel after impulsive loading, $c=7.5 \mathrm{~mm}, \widehat{I}=1.094$ : (a) and (b) show the dry and the wet face sheets; (c) shows a side view; (d) detail of the wet face sheets near boundary. 


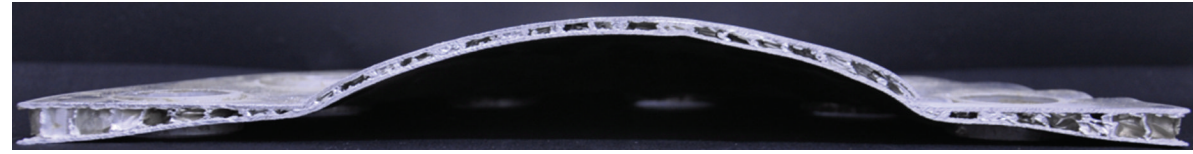

(a)

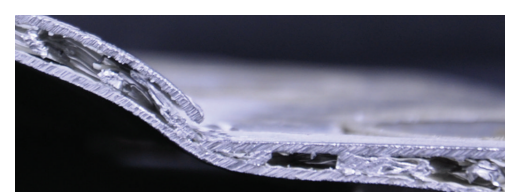

(b)

FIGURE 15: Sandwich panel after impulsive loading: (a) cross section and (b) detail of the wet face sheets near boundary.

TABLE 3: Performance of shock resistance of aluminium sandwich panels.

\begin{tabular}{lcccccccccc}
\hline Number & $c(\mathrm{~mm})$ & $\bar{M}\left(\mathrm{~kg} / \mathrm{m}^{2}\right)$ & $V_{0}\left(\mathrm{~m} / \mathrm{s}^{1}\right)$ & $p_{m s}(\mathrm{MPa})$ & $I_{\mathrm{s}}(\mathrm{kpa} \cdot \mathrm{s})$ & $\widehat{I}$ & $w_{\max }(\mathrm{mm})$ & $(w / L)_{\max }$ & Deformation mode \\
\hline $0810 \# 01$ & 4.0 & 5.20 & 77.0 & 20.47 & 0.549 & 0.630 & 14.7 & 0.193 & Case II \\
$0725 \# 11$ & 4.0 & 5.20 & 81.0 & 21.53 & 0.577 & 0.662 & 15.7 & 0.207 & Case II \\
$0725 \# 07$ & 4.0 & 5.20 & 95.1 & 25.28 & 0.677 & 0.778 & 19.2 & 0.253 & Case III \\
$0725 \# 08$ & 7.5 & 5.36 & 112.3 & 29.85 & 0.800 & 0.891 & 14.9 & 0.196 & Case I \\
$0810 \# 07$ & 7.5 & 5.36 & 131.3 & 34.90 & 0.935 & 1.041 & 20.6 & 0.271 & Case III \\
$0725 \# 09$ & 7.5 & 5.36 & 137.9 & 36.65 & 0.982 & 1.094 & 22.3 & 0.293 & Case III \\
$1016 \# 01$ & 12.3 & 5.58 & 93.4 & 24.83 & 0.665 & 0.712 & 10.1 & 0.133 & Case I \\
$0810 \# 05$ & 12.3 & 5.58 & 122.0 & 32.43 & 0.869 & 0.930 & 13.7 & 0.180 & Case I \\
$0725 \# 10$ & 12.3 & 5.58 & 140.0 & 37.21 & 0.997 & 1.067 & 16.0 & 0.211 & Case I \\
$1016 \# 02$ & 12.3 & 5.58 & 150.6 & 40.03 & 1.073 & 1.147 & 18.0 & 0.237 & Case II \\
\hline
\end{tabular}

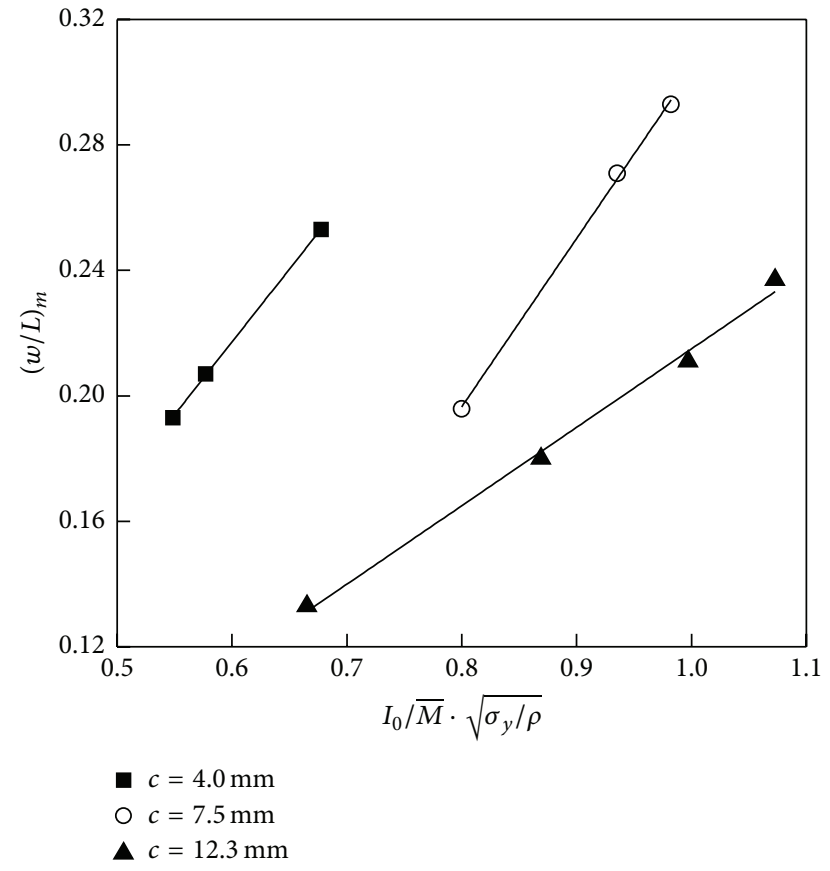

FIGURE 16: Maximum deflection of the dry face sheets of aluminium sandwich panels as a function of the normalized free-field momentum per unit area, $I_{s}$, for a blast pulse in water.

I to Case III. The dimensionless impulse and normalized maximum deflection have been used to obtain the results plotted in Figure 16.

The contrast of numbers $0810 \# 1$ and $1016 \# 2$ shows that although the thickness of core has increased by $8 \mathrm{~mm}$, the mass per unit area of the sandwich panels only was increased by $7.3 \%$. In this case, however, the dimensionless impulse increases by $82.1 \%$, but normalized maximum deflection only has increased by $22.8 \%$. It is obvious that shock resistance of sandwich panels can be improved through increasing the thickness of core, when the panels have the same thickness wet and dry face sheets.

\section{Conclusion}

This paper focused on the study of the response and deformation mode of an aluminium honeycomb sandwich panel subjected to underwater blasting loading using a novel fluidstructure interaction experimental setup. The shock pressure histories were well captured by the dynamic high-pressure transducers at two locations of shock tube. Underwater impulsive loads applied to specimens were analyzed and predicted. 3D DIC technique coupled with high-speed photography is used to obtain the out-of-plane deformation, velocity, and in-plane strain on the dry face sheet of the panels with a frame rate of 50,000 fps.

Results show that the deformation process of aluminium honeycomb sandwich panel presents obvious circular deformation platform in the beginning of the event, which differs from that of monolithic plate. In this case, the dynamic response of sandwich is similar to dynamic response problems of a rigid-perfectly plastic clamped beam with initial transverse velocity.

Based on the observation of the current experiments, there were three typical deformation modes for sandwich panel subjected to underwater impulse. In Mode I, the deformation for both face sheets was homogeneous and the wet face sheet did not appear to have obvious deformation boundary. In Mode II, the wet face sheet's deformation shape exhibited obvious border with dense wrinkle except 
homogeneous deformation, and the whole structure buckling appeared. In Mode III, obvious imprints were observed on the wet face sheet and a partial tear failure occurred at the constraint boundary of the dry face sheet.

Furthermore, it can be verified that there was a direct linear relationship between the normalized maximum deflection and the dimensionless impulse. The shock resistance of sandwich panel is able to be effectively improved by increasing the core layer thickness, while the optimal thickness of face sheets and core layer still need to be explored.

\section{Conflict of Interests}

The authors declare that there is no conflict of interests regarding the publication of this paper.

\section{Acknowledgments}

The authors would like to express their gratitude to Dr. Han Liu, whose efforts were essential to the 3D DIC. This research was supported by the National Natural Science Fund of China (Projects nos. 11272057 and 51209042).

\section{References}

[1] K. M. Stefanick, Laser Welded Lightweight Sandwich Panel Fabrication and Shipyard Applications, Concurrent Technologies, 2005.

[2] A. P. Mouritz, E. Gellert, P. Burchill, and K. Challis, "Review of advanced composite structures for naval ships and submarines," Composite Structures, vol. 53, no. 1, pp. 21-24, 2001.

[3] P. Zhang, Y. S. Cheng, and J. Liu, "Numerical analysis of dynamic response of corrugated core sandwich panels subjected to near-field air blast loading," Shock and Vibration, vol. 2014, Article ID 180674, 16 pages, 2014.

[4] N. A. Fleck and V. S. Deshpande, "The resistance of clamped sandwich beams to shock loading," Journal of Applied Mechanics, Transactions ASME, vol. 71, no. 3, pp. 386-401, 2004.

[5] X. Qiu, V. S. Deshpande, and N. A. Fleck, "Dynamic response of a clamped circular sandwich plate subject to shock loading," Journal of Applied Mechanics, Transactions ASME, vol. 71, no. 5, pp. 637-645, 2004.

[6] J. W. Hutchinson and Z. Y. Xue, "Metal sandwich plates optimized for pressure impulses," International Journal of Mechanical Sciences, vol. 47, no. 4-5, pp. 545-569, 2005.

[7] L. Yueming, A. V. Spuskanyuk, S. E. Flores et al., "The response of metallic sandwich panels to water blast," Journal of Applied Mechanics, Transactions ASME, vol. 74, no. 1, pp. 81-99, 2007.

[8] Z. Xue and J. W. Hutchinson, "A comparative study of impulseresistant metal sandwich plates," International Journal of Impact Engineering, vol. 30, no. 10, pp. 1283-1305, 2004.

[9] X. Qiu, V. S. Deshpande, and N. A. Fleck, "Finite element analysis of the dynamic response of clamped sandwich beams subject to shock loading," European Journal of Mechanics, A/Solids, vol. 22, no. 6, pp. 801-814, 2003.

[10] V. S. Deshpande and N. A. Fleck, "One-dimensional response of sandwich plates to underwater shock loading," Journal of the Mechanics and Physics of Solids, vol. 53, no. 11, pp. 2347-2383, 2005.
[11] G. J. McShane, V. S. Deshpande, and N. A. Fleck, "The underwater blast resistance of metallic sandwich beams with prismatic lattice cores," Journal of Applied Mechanics, vol. 74, no. 2, pp. 352-364, 2007.

[12] Z. Wei, K. P. Dharmasena, H. N. G. Wadley, and A. G. Evans, "Analysis and interpretation of a test for characterizing the response of sandwich panels to water blast," International Journal of Impact Engineering, vol. 34, no. 10, pp. 1602-1618, 2007.

[13] K. P. Dharmasena, D. Queheillalt, H. Wadley et al., "Dynamic response of a multilayer prismatic structure to impulsive loads incident from water," International Journal of Impact Engineering, vol. 36, no. 4, pp. 632-643, 2009.

[14] K. P. Dharmasena, D. T. Queheillalt, H. N. Wadley et al., "Dynamic compression of metallic sandwich structures during planar impulsive loading in water," European Journal of Mechanics: A/Solids, vol. 29, no. 1, pp. 56-67, 2010.

[15] J. LeBlanc and A. Shukla, "Dynamic response and damage evolution in composite materials subjected to underwater explosive loading: an experimental and computational study," Composite Structures, vol. 92, no. 10, pp. 2421-2430, 2010.

[16] J. LeBlanc and A. Shukla, "Dynamic response of curved composite panels to underwater explosive loading: experimental and computational comparisons," Composite Structures, vol. 93, no. 11, pp. 3072-3081, 2011.

[17] J. LeBlanc and A. Shukla, "Response of E-glass/vinyl ester composite panels to underwater explosive loading: effects of laminate modifications," International Journal of Impact Engineering, vol. 38, no. 10, pp. 796-803, 2011.

[18] V. S. Deshpande, A. Heaver, and N. A. Fleck, "An underwater shock simulator," Proceedings of the Royal Society A: Mathematical, Physical and Engineering Sciences, vol. 462, no. 2067, pp. 1021-1041, 2006.

[19] G. J. McShane, V. S. Deshpande, and N. A. Fleck, "Underwater blast response of free-standing sandwich plates with metallic lattice cores," International Journal of Impact Engineering, vol. 37, no. 11, pp. 1138-1149, 2010.

[20] A. Schiffer and V. L. Tagarielli, "One-dimensional response of sandwich plates to underwater blast: fluid-structure interaction experiments and simulations," International Journal of Impact Engineering, vol. 71, pp. 34-49, 2014.

[21] H. D. Espinosa, S. Lee, and N. Moldovan, "A novel fluid structure interaction experiment to investigate deformation of structural elements subjected to impulsive loading," Experimental Mechanics, vol. 46, no. 6, pp. 805-824, 2006.

[22] L. F. Mori, S. F. Lee, Z. Y. Xue et al., "Deformation and fracture modes of sandwich structures subjected to underwater impulsive loads," Journal of Mechanics of Materials and Structures, vol. 2, no. 10, pp. 1981-2006, 2007.

[23] L. F. Mori, D. T. Queheillalt, H. N. G. Wadley, and H. D. Espinosa, "Deformation and failure modes of I-core sandwich structures subjected to underwater impulsive loads," Experimental Mechanics, vol. 49, no. 2, pp. 257-275, 2009.

[24] F. Zhu, L. Zhao, G. Lu, and Z. Wang, "Deformation and failure of blast-loaded metallic sandwich panels-experimental investigations," International Journal of Impact Engineering, vol. 35, no. 8, pp. 937-951, 2008.

[25] R. H. Cole, Underwater Explosions, Princeton University Press, Princeton, NJ, USA, 1948.

[26] V. Tiwari, M. A. Sutton, S. R. McNeill et al., "Application of 3D image correlation for full-field transient plate deformation 
measurements during blast loading," International Journal of Impact Engineering, vol. 36, no. 6, pp. 862-874, 2009.

[27] K. Spranghers, I. Vasilakos, D. Lecompte, H. Sol, and J. Vantomme, "Full-field deformation measurements of aluminum plates under free air blast loading," Experimental Mechanics, vol. 52, no. 9, pp. 1371-1384, 2012.

[28] W. N. Sharpe Jr., Handbook of Experimental Solid Mechanics, Springer, New York, NY, USA, 2008. 

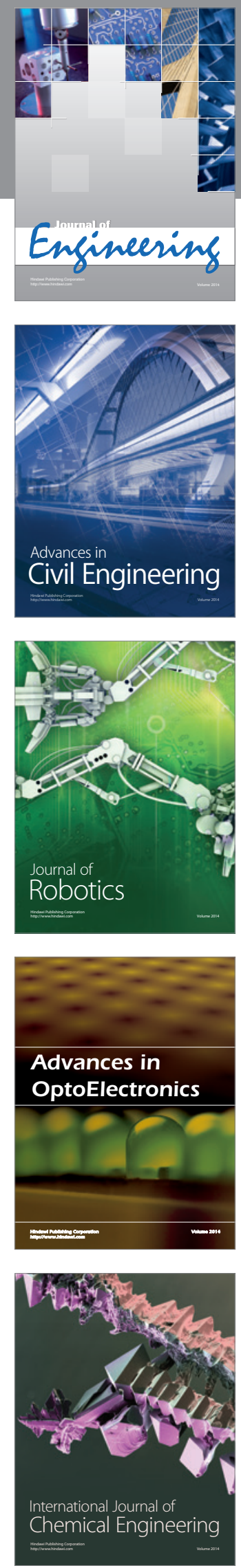

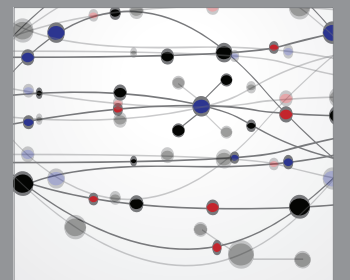

The Scientific World Journal
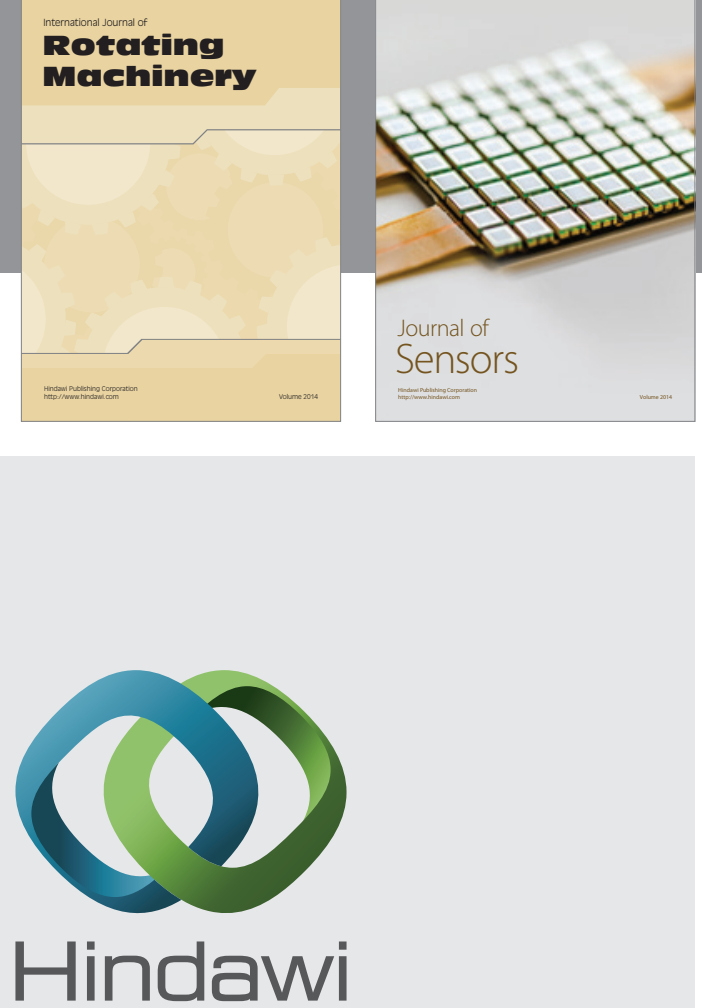

Submit your manuscripts at http://www.hindawi.com
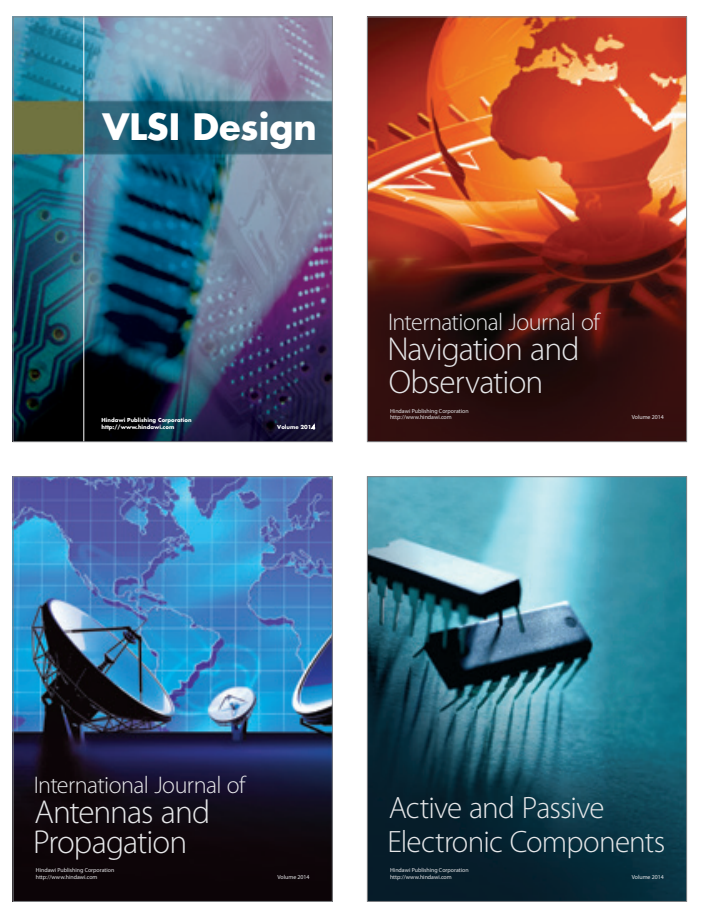
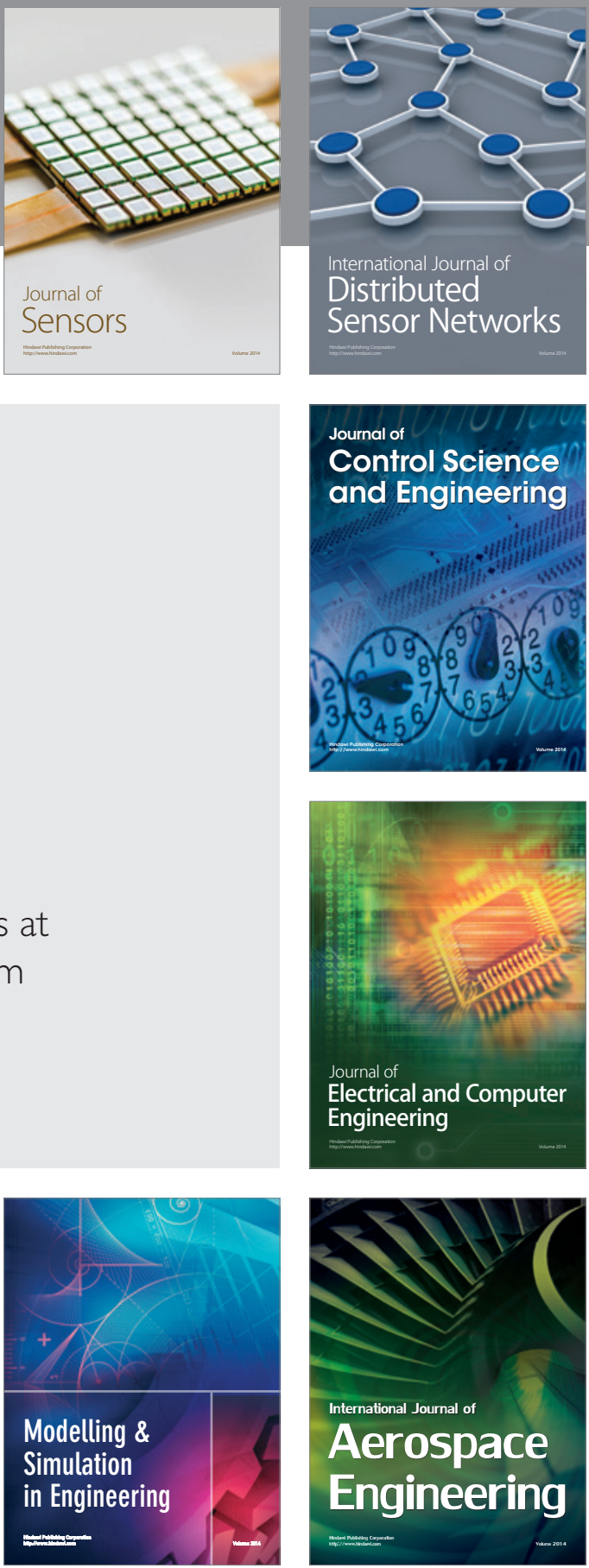

Journal of

Control Science

and Engineering
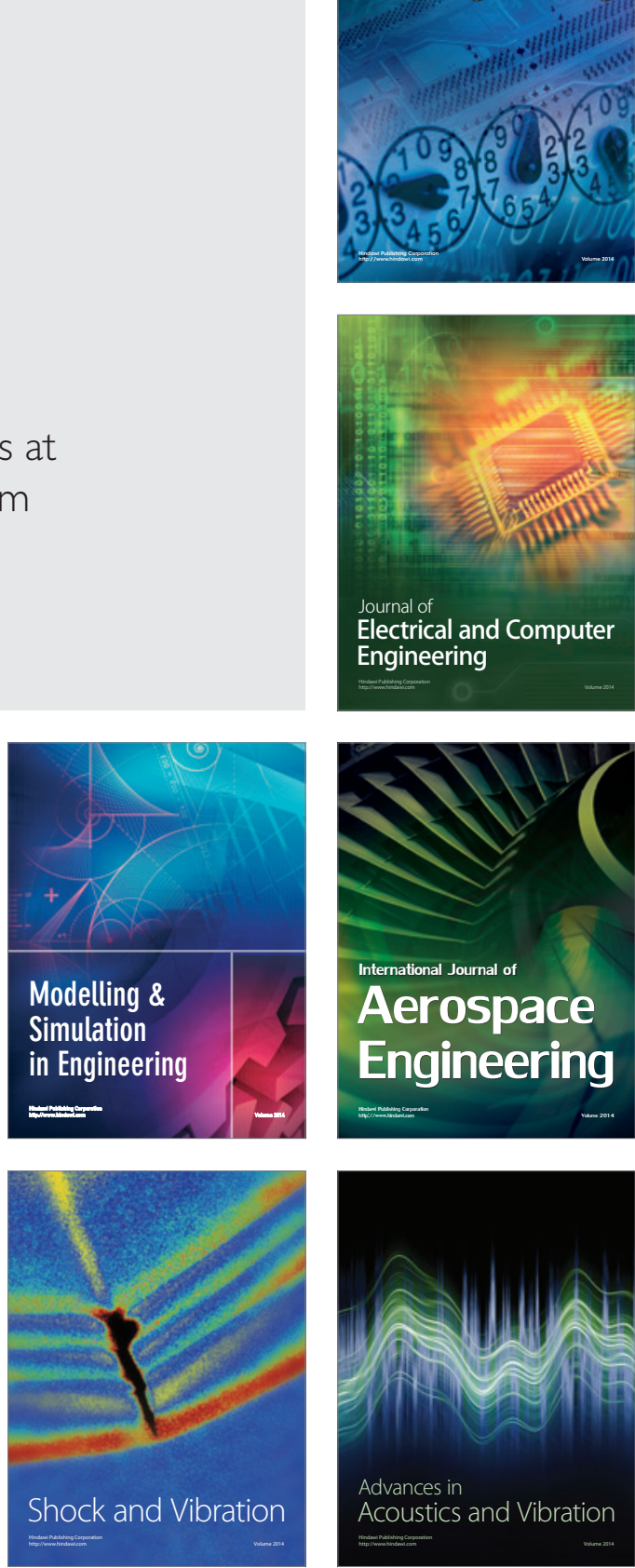